\title{
Natriuretic peptides improve the developmental competence of in vitro cultured porcine oocytes
}

\author{
Yanhao Zhang, Huarong Wang, Wei Liu, Ye Yang, Xiao Wang, Zhiyuan Zhang, Qirui Guo, Chao Wang \\ and Guoliang Xia*
}

\begin{abstract}
Background: Natriuretic peptides (NPs), brain and C type NPs (BNP and CNP), were involved in the maintenance of porcine oocyte meiotic arrest. The present study investigated the effects of NPs on developmental competence of immature porcine oocytes with follicles of different sizes.

Methods: Follicular fluid NP levels were examined by radioimmunoassay. The developmental competence of porcine oocytes was evaluated by cleavage and blastocyst developmental rates after in vitro fertilization (IVF) or parthenogenetic activation (PA) of cumulus oocyte complexes (COCs), which were recovered from follicle with different sizes. NP levels were examined and classified according to the cleavage potential after IVF with COCs released from these follicles.
\end{abstract}

Results: The BNP and CNP concentrations were increased with follicular size in follicular fluid and sustained at the set ranges of $3.0-6.0 \mathrm{~mm}$ follicles compared to $6.1-8.0 \mathrm{~mm}$ follicles. The oocytes developed from 3.0 to $6.0 \mathrm{~mm}$ follicles demonstrated increased embryo cleavage and blastocyst ratios after IVF, with an increased follicle size $(P<0.05)$. Moreover, BNP and CNP significantly promoted the blastocyst developmental rates of $3.0-6.0 \mathrm{~mm}$ follicles, but could not improve the developmental competence of oocytes from 6.1 to $8.0 \mathrm{~mm}$ follicles due to low NP levels. The COCs from 3.0 to $4.0 \mathrm{~mm}$ follicles were pre-incubated in $100 \mathrm{ng} / \mathrm{ml}$ of BNP and CNP media for $20 \mathrm{~h}$ before regular in vitro maturation, which demonstrated 2 to 3 folds higher developmental competencies in both PA and IVF groups compared to respective controls $(P<0.01)$.

Conclusions: The effects of BNP and CNP supplementation in the pre-maturation culture media (PMC) on porcine developmental competence from COCs in follicles of different sizes were different and improved the developmental competence of porcine oocytes from small antral follicle in vitro.

Keywords: Natriuretic peptide, Oocyte, Cytoplasmic maturation, Porcine

\section{Summary sentence}

The effects of BNP and CNP supplementation in the prematuration culture (PMC) media on the developmental competence of cumulus oocyte complexes (COCs) recovered from porcine follicles of different sizes were different. The developmental competence of porcine oocytes from small antral follicles was improved by BNP and CNP in vitro.

\footnotetext{
* Correspondence: glxiachina@sohu.com

State Key Laboratory of Agrobiotechnology, College of Biological Sciences, China Agricultural University, Beijing 100193, People's Republic of China
}

\section{Background}

In mammals, the developmental competence of oocytes is acquired through completion of both nuclear and cytoplasmic maturation [1, 2]. Oocytes in antral follicles are maintained in meiotic arrest, known as the germinal vesicle (GV) stage, for a prolonged period of time from diplotene stage of prophase I till the preovulatory stage [2]. During the retrieval process of oocytes from their follicles, the GV-stage oocytes spontaneously undergo nuclear maturation in vitro, where it progresses through the first meiotic division and reach till the second metaphase (MII). These oocytes, however, attain nuclear maturation 
before reaching optimal cytoplasmic maturity $[3,4]$. Previous studies have demonstrated that only a small portion of in vitro matured (IVM) oocytes develop into blastocysts, whereas those oocytes matured in vivo counterparts have much higher embryo developmental rates in several species $[2,4]$. This indicated poor nuclear and/or cytoplasmic maturation in the current oocyte IVM systems [2-4].

To ensure developmental competence, both the nuclear and cytoplasmic maturation of oocytes should co-ordinate and proceed independently [2]. Cytoplasmic maturation is not as clearly defined as the meiotic process as the process of cytoplasmic maturation involves organelle reorganization, cytoskeleton dynamics and molecular maturation during oocyte growth and meiosis [5]. It is believed that an extension of the culture period by blocking meiosis progression could allow the completion of intraoocyte cytoplasmic changes and oocyte development $[4,6,7]$. The prematuration culture (PMC) of oocytes with pharmacological phosphodiesterase 3 (PDE3) specific inhibitors such as cilostamide and rolipram $[4,8]$ retards nuclear maturation, which in turn allows time for ooplasmic maturation to catch up and results in better synchronization of nuclear and cytoplasmic compartments $[6,7,9]$. Therefore, optimizing the PMC conditions may help to refine the culture output for clinical use.

The NPs are a family of widely distributed, but evolutionarily conserved, polypeptide mediators that exert a range of effects throughout the body [10]. Atrial natriuretic peptide (ANP) was discovered by showing that atrial extracts contain a potent blood pressure decreasing component [11]; whereas brain natriuretic peptide (BNP) was originally purified and sequenced from extracts of porcine brain tissue and hence it was named "brain natriuretic peptide" [12]; and C-type natriuretic peptide (CNP) was initially purified and sequenced from porcine brain extracts [13]. There is growing realization that NP actions go far beyond volume and blood pressure homeostasis. Their pleiotropic effects include a significant role in regulating the female reproduction [14]. Of all the three NP types, CNP is mainly synthesized inside the mural granulosa cells and its cognate receptor (NPR2) is present in both the cumulus and granulosa cells $[8,15-18]$. CNP functions in blocking the meiosis in caprine, mouse and bovine [1, 8, 14], whereas in porcine, both BNP and CNP are required for porcine oocyte meiotic arrest $[16,19,20]$. The NPs are secreted into the follicular fluid and are held at appropriate concentrations until ovulation. However, whether these NPs contribute to oocyte cytoplasmic maturation has not been demonstrated in vivo till date.

Binding of CNP to NPR2 is primarily expressed in the cumulus cells and in turn increases cyclic guanosine monophosphate (cGMP) concentrations in the cumulus cells. Through the gap junctions, cGMP diffuses into the oocytes and inhibits the activity of PDE3A, thus preventing the degradation of cyclic adenosine monophosphate (cAMP). Elevated cAMP levels maintain meiotic arrest until the preovulatory luteinizing hormone (LH) surge induces the resumption of meiosis $[1,21]$. Increasing the cAMP concentration during IVM of porcine oocytes improves maturation of cumulus and subsequent fertilization in vitro [22]. Natriuretic peptide precursor C (NPPC) promotes gap junction-mediated communication (GJC) between the oocyte and surrounding cumulus cells [8]. And bidirectional communication between oocytes and follicle cells ensure oocyte developmental competence [4, 23]. However, controversy still remains in the improvement of blastocyst rate of in vitro cultured oocytes in between bovine and caprine or mouse $[1,8,21]$.

The present study examines the presence of NPs in the follicles of different sizes. The data from different concentrations of BNP and CNP in the porcine follicular fluid of cleaved embryos and non-cleaved embryos, which resulted from individually culturing of cumulus oocyte complexes $(\mathrm{COC})$ from single follicle in vitro following parthenogenetic activation (PA) or in vitro fertilization (IVF) has been presented. The different effects of NPs on the developmental competence of immature porcine oocytes in follicles of different sizes were evaluated. The results implied that the oocyte developmental competence was more significantly improved by PMC of oocytes collected from the small antral porcine follicles with NPs at physiological concentration.

\section{Methods}

\section{Chemicals}

Unless specified, all chemicals were purchased from Sigma-Aldrich (St. Louis, MO, USA). The pregnant mare's serum gonadotropin (PMSG) and human chorionic gonadotropin (hCG) were obtained from Sansheng Pharmaceutical Co. Ltd. (Ningbo, China).

\section{Animals, oocyte collection, classification and measurement}

Ovaries were obtained from 6- to 12-month-old gilts at a local slaughterhouse, which were transported to our laboratory in phosphate buffered saline supplemented with $100 \mathrm{U} / \mathrm{mL}$ penicillin (Huabei Medical, Jizhou, China) and $50 \mathrm{mg} / \mathrm{mL}$ streptomycin sulfate (Sigma, St. Louis, $\mathrm{MO})$ at $38.5^{\circ} \mathrm{C}$. Cells used in vitro were derived from these tissues.

The follicles were dissected from the ovarian cortex at room temperature using scissors, scalpels and tweezers. During dissection, follicles were kept in washing medium [TCM-199 with Hank's salts supplemented with $10 \%$ of fetal calf serum (FCS)]; GIBCO BRL, Burlington, ON, Canada) on a warm plate at $38.5{ }^{\circ} \mathrm{C}$. The follicles were 
measured using a graduated eyepiece (OSM-4; Olympus, Tokyo, Japan) and were classified morphologically and divided into groups according to their diameter: 3.0-4.0, 4.1-5.0, 5.1-6.0 and 6.1-8.0 mm. The criteria used for follicle selection were: (1) the presence of extensive and fine vascularisation; and (2) a shiny and translucent appearance. After follicular rupture, the presence of granulosa cells with a regular and healthy appearance and no freefloating particles in the follicular fluid were also used as a selection criterion. COCs were released by rupturing the follicles. Only COCs with a homogeneous granulated cytoplasm and at least three layers of compact of cumulus cells were used in the present study. For measurement, COCs were denuded by repeated pipetting and oocyte diameter was evaluated with a graduated eyepiece.

\section{Pre-maturation culture (PMC)}

The pre-maturation culture of the oocyte was designed to retard nuclear maturation during the in vitro porcine oocyte culture. BNP-32 (catalog \# B6651) and CNP-22 (catalog \# N8768) were purchased from Sigma. The culture medium was divided into two portions for different assays. Briefly, the PMC medium was composed of basal medium plus BNP (PMC- BNP) or CNP (PMC- CNP) at a final concentration of $100 \mathrm{ng} / \mathrm{mL}$ or cilostamide $(10 \mu \mathrm{M})$ [24] in the culture medium. All cultures were carried out in a humidified atmosphere at $38.5{ }^{\circ} \mathrm{C}$ with $5 \% \mathrm{CO}_{2}$ in air. All COCs were cultured singly in $20 \mu \mathrm{L}$ droplets covered with mineral oil.

\section{Porcine COCs culture and assessment of nuclear maturation}

The basal culture medium containing $0.5 \mathrm{~mL}$ of TCM199 medium (Gibco, Life Technologies, CA, USA) was supplemented with sodium pyruvate $(0.23 \mathrm{mmol} / \mathrm{L} ;$ Sigma $)$, glutamine ( $2 \mathrm{mmol} / \mathrm{L}$; Sigma), lyophilized crystalline BSA (3 mg/mL; Sigma), penicillin G $(100 \mathrm{U} / \mathrm{mL}$; Huabei Medical, Jizhou, China) and streptomycin sulfate $(50 \mathrm{mg} /$ $\mathrm{mL}$; Sigma). For FSH-induced maturation assay, the COCs were cultured in the above medium supplemented with FSH (0.05 U/mL; Sigma).

After the culture preparation, the oocytes were harvested, fixed in acetic acid/ethanol $(1 / 3 \mathrm{v} / \mathrm{v})$ for $48 \mathrm{~h}$, and stained with $1 \%(\mathrm{w} / \mathrm{v})$ orcein prior to phase contrast microscopic examination (200×) for evaluation of chromatin configuration. The oocyte nuclear maturation status was classified as: 1) GV stage oocyte when displaying a germinal vesicle; 2) germinal vesicle breakdown (GVBD) stage oocyte when displaying a germinal vesicle breakdown and condensed chromatin or metaphase II (M II) stages were identified by the presence of an extruded polar body.
In vitro maturation (IVM) and In vitro fertilization (IVF) by standard

IVF of the porcine oocyte was carried as described previously. Briefly, the fertilization medium used was modified Pig-FM consisting of $\mathrm{NaCl}$ ( $90 \mathrm{mM}$; Sigma), $\mathrm{KCl}$ (12 mM; Sigma), $\mathrm{NaHCO}_{3}$ (25 mM; Sigma), $\mathrm{NaH}_{2} \mathrm{PO}_{4}$ (0.5 mM; Sigma), $\mathrm{MgSO}_{4}$ (0.5 mM; Sigma), sodium lactate (10 mM; Kanto Chemical Co., Inc., Tokyo, Japan), and $10 \mathrm{mM}$ Hepes modified further by Suzuki [25] by the addition of $\mathrm{CaCl}_{2}(8 \mathrm{mM}$; Sigma), sodium pyruvate (2 Mm; Sigma), caffeine (2 mM; Sigma) and BSA (5 mg/ $\mathrm{mL}$; fraction V; Sigma). The same batch of frozen semen from the epididymis of a single boar (Beijing swine breeding center) was used for these experiments.

Frozen thawed spermatozoa were pre-incubated for $15 \mathrm{~min}$ at $38.5{ }^{\circ} \mathrm{C}$ in TCM199 with Earle's salts adjusted to $\mathrm{pH}$ 7.8. A portion $(10 \mu \mathrm{L})$ of the pre-incubated spermatozoa was introduced into $90 \mu \mathrm{L}$ of Pig-FM containing 20 COCs showing expanded cumulus cells. The final sperm concentration was adjusted to $1 \times 10^{5}$ cells/ $\mathrm{mL}$. The COCs were co-incubated with spermatozoa at $38.5{ }^{\circ} \mathrm{C}$ under $5 \% \mathrm{CO}_{2}$ for $5 \mathrm{~h}$. After co-incubation, the oocytes were freed from the surrounding cumulus cells and attached spermatozoa, and transferred into the porcine zygote medium (PZM-3; IFP, Yamagata, Japan) [26], covered with mineral oil, and kept under $5 \% \mathrm{CO}_{2}$ atm at $38.5{ }^{\circ} \mathrm{C}$. The presumptive zygotes were cultured in PZM-3 before evaluation of their qualities showing a homogeneous or saturated density of lipid droplets and intact zona pellucida. The percentages of embryos cleaved at or beyond the 2-cell stage, and those that developed into blastocysts, were assessed under a stereomicroscope 2 or 7 days after insemination, respectively. At the end of culture, an embryo with clear blastocoele was defined as a blastocyst.

\section{Parthenogenetic activation (PA)}

PA of cultured porcine oocyte was performed according to Kwak et al. [26]. Briefly, after in vitro maturation, the MII-stage oocytes of each group were denuded as described previously and washed twice with activation media (280 mM mannitol solution containing $0.01 \mathrm{mM} \mathrm{CaCl} 2$ (Sigma) and $0.05 \mathrm{mM} \mathrm{MgCl} 2$ (Sigma). The oocytes were transferred in between the electrodes (ECM2001, BTX, USA), covered with the activation medium, and activated with two pulses of $120 \mathrm{~V} / \mathrm{mm}$ direct current for 60 microseconds. Then the oocytes were cultured in PZM- 3 covered with mineral oil under $5 \% \mathrm{CO}_{2}$ at $38.5{ }^{\circ} \mathrm{C}$ for 7 days for evaluating their developmental competence.

\section{RNA extraction and quantitative real-time PCR}

The follicles visible on the surface of the ovaries were isolated mechanically. Cumulus oocyte complexes (COCs) were punctured out from follicles. The cumulus 
and granulosa cells were pipetted and stored at $-80{ }^{\circ} \mathrm{C}$ until RNA extraction. For each follicle size group, four or five pooled samples from 20 follicles and their corresponding cumulus cells were stored for subsequent analysis.

Total RNA was isolated using TRIzol (Life Technologies, Carlsbad, CA) according to the manufacturer's protocol. Quantification and quality analysis of total RNA isolated from the above samples were determined using Nanodrop (Thermo Im Heiligen Feld 17, Germany). Total RNA (1 mg) from each sample was incubated for $20 \mathrm{~min}$ at $25{ }^{\circ} \mathrm{C}$ with $0.5 \mathrm{U}$ DNase I (Invitrogen) before reverse transcription to eliminate genomic DNA contamination. RT of the RNA was carried out using oligo (dT) with Moloney Murine Leukaemia Virus Reverse Transcriptase (Promega, Madison, WI, USA) according to the manufacturer's instructions.

Reverse transcription proceeded for $1 \mathrm{~h}$ at $42{ }^{\circ} \mathrm{C}$. DNA was amplified by an initial incubation at $72{ }^{\circ} \mathrm{C}$ for $5 \mathrm{~min}$ followed by $24-33$ cycles of denaturation at $72{ }^{\circ} \mathrm{C}$ for $30 \mathrm{~s}$, annealing at different temperatures were for $30 \mathrm{~s}$, which were presented in Additional file 1: Table S1, and extension at $72{ }^{\circ} \mathrm{C}$ for $30 \mathrm{~s}$, and a final extension at $72^{\circ}$ $\mathrm{C}$ for $5 \mathrm{~min}$. $\beta$-Actin was used as the internal standard. Amplified products were sequenced (Invitrogen, Beijing, China) to confirm specificity.

Quantitative real-time PCR (qRT-PCR) was performed in 96-well plates (Applied Biosystems, Foster City, CA) in reaction volumes of $25 \mu \mathrm{L}$ containing $12.5 \mu \mathrm{L}$ SYBR Green PCR Master Mix (Applied Biosystems, Foster City, CA), 15 ng cDNA, appropriate primers (Additional file 1: Table S1), and nuclease-free water. PCR was performed on an ABI 7500 Sequence Detection System (Applied Biosystem, Foster City, CA) using the following parameters: $10 \mathrm{~min}$ at $95{ }^{\circ} \mathrm{C}$ followed by 40 cycles of $15 \mathrm{~s}$ at $95{ }^{\circ} \mathrm{C}$ and $1 \mathrm{~min}$ at $60{ }^{\circ} \mathrm{C}$. All test data were normalized to levels of glyceraldehyde-3-phosphate dehydrogenase (GAPDH) transcription. A melt curve was generated after PCR at temperature increments of $0.5^{\circ} \mathrm{C}$ every 2 cycles $\left(62\right.$ cycles total) starting at $65{ }^{\circ} \mathrm{C}$, with fluorescence acquisition after each step. The PCR products were separated by electrophoresis in a $1 \%$ agarose gel and visualized by ethidium bromide staining. Relative intensities were quantified using Gel-Pro Analyzer 4.0 software (Media Cybernetics, Inc., Bethesda, MD, USA). The relative target gene expression level in each sample was calculated using the $2^{-\Delta \Delta} \mathrm{Ct}$ formula, as described previously [16].

\section{Radioimmunoassay (RIA) for detection of BNP-26 and CNP-22 in porcine follicular fluid}

Porcine follicular fluid was centrifuged at $10,000 \mathrm{~g}$ at $4{ }^{\circ} \mathrm{C}$ for $15 \mathrm{~min}$ and the supernatants were collected in the centrifuge tubes containing aprotinin (Phoenix Biotech; catalog \#RK-APRO; $0.6 \mathrm{TIU} / \mathrm{ml}$ ) and stored at $-80{ }^{\circ} \mathrm{C}$ prior to the assay. Natriuretic peptide levels in the follicular fluid were measured with the aid of commercial RIA kits: porcine BNP-26 (Sigma, \#T-011-10) and CNP-22 (Sigma, Human, Rat, Mouse, Porcine; \#T-012-03). These RIA kits showed no cross reactivity with each other. The sensitivity of the BNP assay was $47.1 \mathrm{pg} / \mathrm{mL}$ and that of the CNP assay was $17.9 \mathrm{pg} / \mathrm{mL}$. In our experiments, BNP was measured with an intra-assay variation of less than $4.3 \%$ and an inter-assay variation of less than $8.7 \%$. CNP was measured with an intra-assay variation of $5 \%$ and an inter-assay variation of $12.2 \%$.

\section{Culture model individual COC from single follicle and single embryo culture in vitro}

A single COC in vitro culture model was used for tracking the developmental fate of the oocyte (Fig. 2, a), where the culture medium drops were connected to each other by culture medium with composed net was designed. A single COC/embryo in one droplet that was surrounded by neighboring and connected droplets of every $10 \mathrm{COCs} /$ embryos were placed. The bridge of culture medium between single COC/embryo-containing drops and groups of $10 \mathrm{COCs} /$ embryos-containing drops was made of culture medium, which is considered to be the same as the single COC/embryo or $10 \mathrm{COCs} / \mathrm{embryos}$-containing drops. The cleavages and blastocyst rates of oocytes cultured in this culture model were higher than a single COC that was placed in one droplet. The concentrations of BNP and CNP in the follicular fluid of cleaved embryos and noncleaved embryos that resulted from culturing individual COCs from single follicle in vitro following PA or IVF were measured. The individual culture system allowed for investigating the correlation of developmental ability of each $\mathrm{COC}$ with the concentrations of BNP and CNP in the original follicle.

\section{IVM of Small antral follicle-derived COCs}

The criteria used for selection of porcine small antral follicles $(3.0-4.0 \mathrm{~mm})$ (Fig. 4 , a) were shiny and translucent in appearance. After follicular rupture, the presence of granulosa cells with a regular and healthy appearance and no free-floating particles in the follicular fluid were also used as a selection criterion. The COCs from small antral follicle were cultured either by standard IVM for $46 \mathrm{~h}$ or $66 \mathrm{~h}$ (as negative controls), or precultured with PMCI-cilostamide $(10 \mu \mathrm{M}) 20 \mathrm{~h}$ plus IVM $46 \mathrm{~h}$ (as positive controls) and pre-cultured with PMCI-BNP/CNP (100 ng/mL) $20 \mathrm{~h}$ plus IVM $46 \mathrm{~h}$ (as experimental groups). The developmental competence of oocytes was investigated by PA and IVF assays. 


\section{Experimental design}

Expression of NPPB and NPPC MRNAs in the cumulus and granulosa cells as well as the NP levels inside the follicular fluid with follicular size, and could be associated with the oocyte developmental competence

In order to study the relationship between NP levels and oocyte developmental competence in follicles of 3.0 $8.0 \mathrm{~mm}$ in size, the follicles were dissected and distributed into four groups according to the diameter and were as follows: 3.0 - 4.0, 4.1 - 5.0, 5.1 - 6.0 and 6.1 $8.0 \mathrm{~mm}$. IVF and IVM was performed with the help of standard COCs from follicles of different sizes to evaluate oocyte developmental competence. In the meantime, the NPPB, NPPC and NPR2 gene expression levels in the somatic cells of the follicles were examined by using real-time polymerase chain reaction (PCR) and the NP levels inside the follicular fluids were examined by the radioimmunoassay (RIA).

\section{The concentrations of BNP and CNP in the follicular fluid containing oocytes that generated cleaved embryos and non-cleaved embryos}

To determine the correlation of developmental competence of each COC to the BNP and CNP concentrations in the original follicle, a single $\mathrm{COC}$ in vitro maturation was performed in a particular culture system as described above. To examine if single follicles have various developmental outcomes with different concentrations of NPs within the follicular fluid, the NP levels in each follicular fluid was examined and classified according to the cleavage potential after IVF with COCs coming from such follicles. A single COC in vitro culture model for tracking the developmental fate of the oocyte was shown in (Fig. 2, a). After standard IVM, the oocyte developmental competence was examined by PA and IVF assays individually.

\section{The different effects of NPs on the developmental competence of immature porcine oocytes from follicles of different sizes}

In order to clarify the effect of whether individual or a combination of NPs on the developmental competence, a final concentration that reached the physiological level in order to achieve similar inhibitory effects on oocyte meiosis with different combinations of BNP and CNP, including $100 \mathrm{ng} / \mathrm{mL} \mathrm{BNP}$ alone; $70 \mathrm{ng} / \mathrm{mL} \mathrm{BNP} \mathrm{+}$ $30 \mathrm{ng} / \mathrm{mL}$ CNP; $50 \mathrm{ng} / \mathrm{mL} \mathrm{BNP}+50 \mathrm{ng} / \mathrm{mL} \mathrm{CNP} ; 30 \mathrm{ng} /$ $\mathrm{mL} \mathrm{BNP} \mathrm{+} 70 \mathrm{ng} / \mathrm{mL} \mathrm{CNP}$; and $100 \mathrm{ng} / \mathrm{mL} \mathrm{CNP}$ alone were added to the in vitro culture media. In order to evaluate the effects of BNP and CNP supplementation in PMC culture media on developmental competence of porcine oocytes from COCs, COCs from 3.0 - 8.0, 3.0 4.0, $4.1-6.0,6.1-8.0 \mathrm{~mm}$ follicles were cultured in the presence of either by BNP, CNP or cilostamide in vitro.
The porcine COCs were cultured either by standard IVM for $46 \mathrm{~h}$ (as negative controls), or pre-cultured with PMCI-cilostamide $20 \mathrm{~h}$ plus IVM $46 \mathrm{~h}$ (as positive controls) and pre-cultured with PMCI-BNP/CNP $20 \mathrm{~h}$ plus IVM $46 \mathrm{~h}$ (as experimental groups). The developmental competence of oocytes was investigated by PA and IVF assays.

\section{Statistical analysis}

All experiments were performed at least three times, and values are shown as mean \pm SEM. Data were analyzed by $t$-test or analysis of variance (ANOVA) with StatView software (SAS Institute, Inc., Cary, NC). The groups were compared using the Holm-Šidák test. A p value less than 0.05 was considered to be statistically significant.

\section{Results}

Expression of NPPB and NPPC mRNA in the cumulus and granulosa cells as well as the NP levels inside the follicular fluid with follicular size could be associated with the oocyte developmental competence

The results showed that the cleavage and blastocyst rates were increased with the dimension of the follicle from 3.0 to $6.0 \mathrm{~mm}$. Oocytes from follicle size of $4.1-6.0 \mathrm{~mm}$ demonstrated significant developmental competence than $6.1-8.0 \mathrm{~mm}$ in size $(P<0.001)$ (Table 1). The relative abundance of $N P P B$ and $N P P C$ mRNAs were increased gradually in the cumulus and granulosa cells with the follicle size (Fig. 1, b, c). But the expression of NPPA was decreased with the increase in the follicular diameter (Fig. 1, a). The expression of NPR2 demonstrated no significant difference with the follicular cumulus and granulosa cells among follicles of different diameters (Fig. 1, d).

The follicles were classified according to the differences in diameter. The concentrations of both BNP and $\mathrm{CNP}$ in the follicular fluid were similar to each other and were sustained at set ranges (55 to $59 \mathrm{ng} / \mathrm{mL}$ for $\mathrm{BNP}$ and 36 to $40 \mathrm{ng} / \mathrm{mL}$ for $\mathrm{CNP}$ ) in $3.0-6.0 \mathrm{~mm}$ follicles, but all were significantly higher $(P<0.05)$ than those of $6.1-8.0 \mathrm{~mm}$ follicles $(40 \mathrm{ng} / \mathrm{mL}$ and $32 \mathrm{ng} / \mathrm{mL}$, respectively, Table 2 ).

Table 1 The cleavage and blastocyst rates on day 2 and day 7 after IVF with the dimension of follicle from 3.0 to $8.0 \mathrm{~mm}$ (mean \pm S. E. M.)

\begin{tabular}{llcc}
\hline Follicle diameter $(\mathrm{mm})$ & oocytes $(\mathrm{n})$ & cleaved oocytes (\%) & blastocysts (\%) \\
\hline $3.0-4.0$ & 215 & $11.2 \pm 2.7^{\mathrm{a}}$ & $3.6 \pm 1.67^{\mathrm{a}}$ \\
$4.1-5.0$ & 201 & $37.5 \pm 2.3^{\mathrm{b}}$ & $10.1 \pm 1.8^{\mathrm{b}}$ \\
$5.1-6.0$ & 235 & $41.64 \pm 1.6^{\mathrm{b}}$ & $13.3 \pm 2.9^{\mathrm{c}}$ \\
$6.1-8.0$ & 206 & $30.9 \pm 2.2^{\mathrm{c}}$ & $8.3 \pm 2.5^{\mathrm{d}}$ \\
\hline
\end{tabular}

abcd Means in the same column with different superscripts were significantly different $(p<0.05)$ 

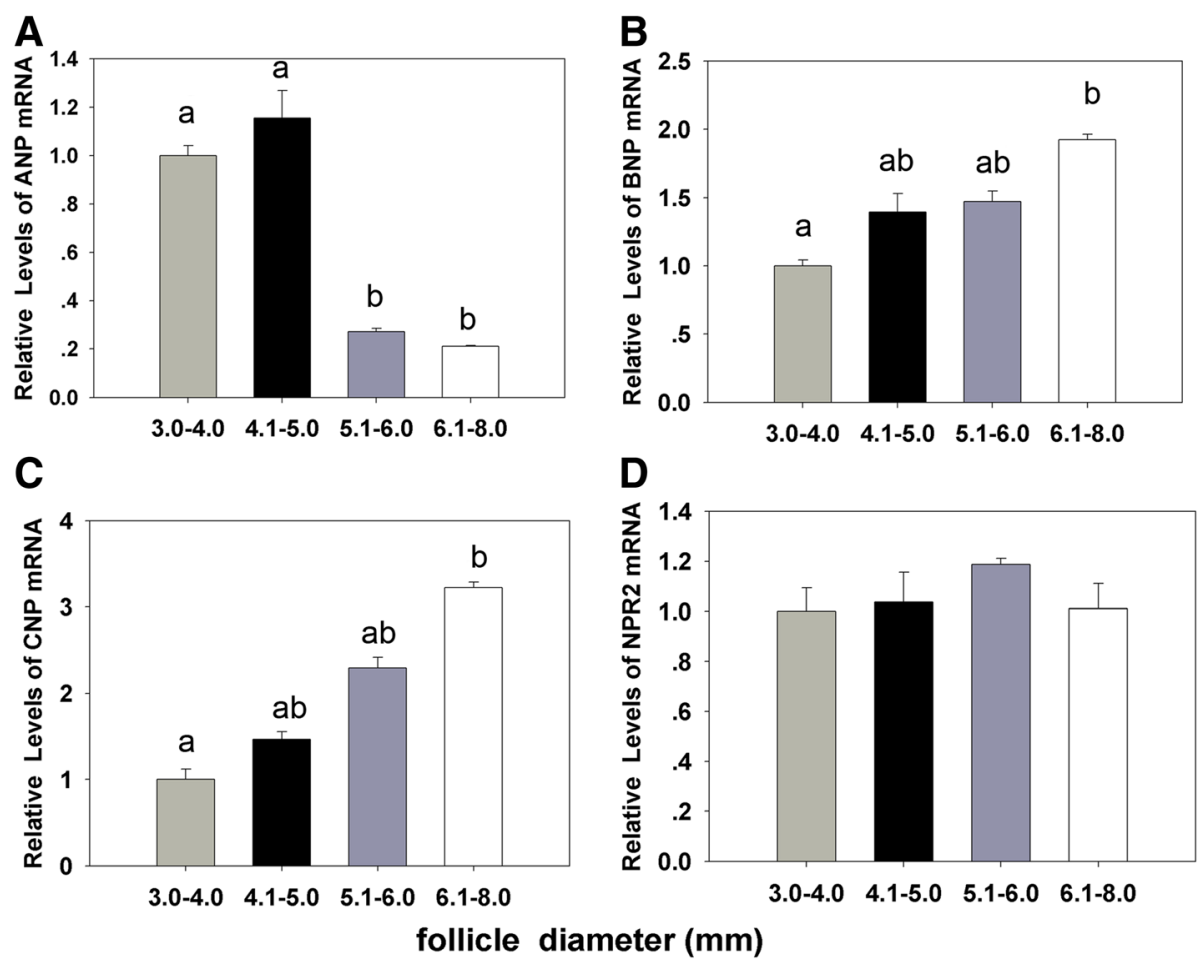

Fig. 1 The relationship between natriuretic peptides levels and oocyte development potential in follicles sized from 3.0 to $8.0 \mathrm{~mm}$. a, b, c, d The relative expressions of NPPA, NPPB, NPPC and NPR2 genes in porcine cumulus and granulosa cells from different sized follicles. The data are the mean \pm SEM and are normalized against the CYC-A gene, with results expressed relative to the control sample using the $2^{-\Delta \Delta} \mathrm{Ct}$ method with efficiency correction. Different columns with various superscript letters differ significantly $(P<0.05)$

The concentrations of BNP and CNP in the follicular fluid containing oocytes that generated cleaved embryos and non-cleaved embryos are significantly different

The concentrations of BNP or CNP in each follicle of cleaved embryos and non-cleaved embryos by culturing individual COCs from single follicle in vitro following PA or IVF individually was shown in Fig. 2, b-e. The concentrations of BNP in the follicular fluid containing oocytes that generated cleaved embryos were $30-70 \mathrm{ng} / \mathrm{mL}$ in PA $(\mathrm{n}=6)$, (Fig. 2, b) and 45-65 ng/mL in IVF (Fig. 2, c). The concentrations of CNP were $25-45 \mathrm{ng} / \mathrm{mL}$ (Fig. 2, d) in PA $(n=6)$ and $30-45 \mathrm{ng} / \mathrm{mL}$ in $\operatorname{IVF}(n=9)$ (Fig. 2, e). In

Table 2 The concentrations of BNP and CNP in follicular fluid from 3.0 to $8.0 \mathrm{~mm}$ follicle were examined by RIA assay (mean \pm S. E. M.)

\begin{tabular}{lll}
\hline $\begin{array}{l}\text { Follicle diameter } \\
(\mathrm{mm})\end{array}$ & $\begin{array}{l}\text { BNP } \\
(\mathrm{mg} / \mathrm{ml})\end{array}$ & $\begin{array}{l}\text { CNP } \\
(\mathrm{mg} / \mathrm{ml})\end{array}$ \\
\hline $3.0-4.0$ & $55.9 \pm 2.8^{\mathrm{a}}$ & $36.3 \pm 2.4^{\mathrm{a}}$ \\
$4.1-5.0$ & $56.8 \pm 5.4^{\mathrm{a}}$ & $37.7 \pm 3.8^{\mathrm{a}}$ \\
$5.1-6.0$ & $58.9 \pm 3.4^{\mathrm{a}}$ & $39.4 \pm 2.6^{\mathrm{a}}$ \\
$6.0-8.0$ & $39.6 \pm 6.7^{\mathrm{b}}$ & $32.3 \pm 2.8^{\mathrm{b}}$ \\
\hline
\end{tabular}

At least three follicles were examined at each time point for each experiment. ${ }^{\mathrm{ab}}$ Means in the same column with different superscripts were significantly different $(p<0.05)$ addition, the NP levels in non-cleaved oocytes differed obviously compared to the cleaved ones. The non-cleaved follicles were divided into two groups: a group with higher NP levels (non-cleaved-h) and a group with lower NP levels (non-cleaved-1) in comparison to the cleaved ones (Fig. 2, f, g).

Different effects of BNP and CNP on the developmental competence of immature porcine oocytes from follicles of different size in vitro

The COCs from 3.0 to $8.0 \mathrm{~mm}$ follicles were used for the assay. Porcine matured oocytes were cultured in TCM199 medium with or without combining BNP and $\mathrm{CNP}$ with FSH for $24 \mathrm{~h}$, and the effects were evaluated by examining the oocytes in the GV stage (Fig. 3, a,b). The results showed that both individual and combination of BNP and CNP have similar inhibitory effects in response to FSH stimulation of COCs (Table 3).

After IVF and embryo culture, the COCs from 3.0 to $8.0 \mathrm{~mm}$ follicle showed no significant differences in the blastocyst rate in different treatments (Table 4). In the IVF experiment, the oocyte cleavage rates of COCs from 3.0 to $4.0 \mathrm{~mm}$ was significantly $(P<0.01)$ higher in the PMC-BNP/CNP group compared to the controls (Table 5). Similar to the cleavage rates, the blastocyst 
A

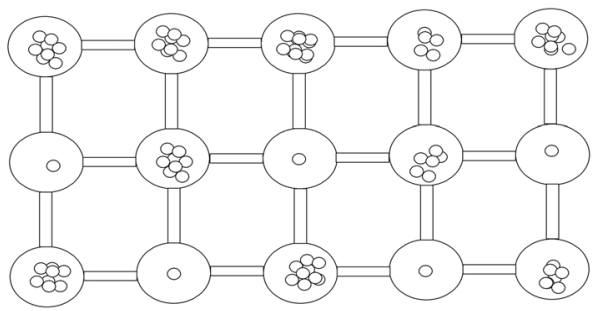

B
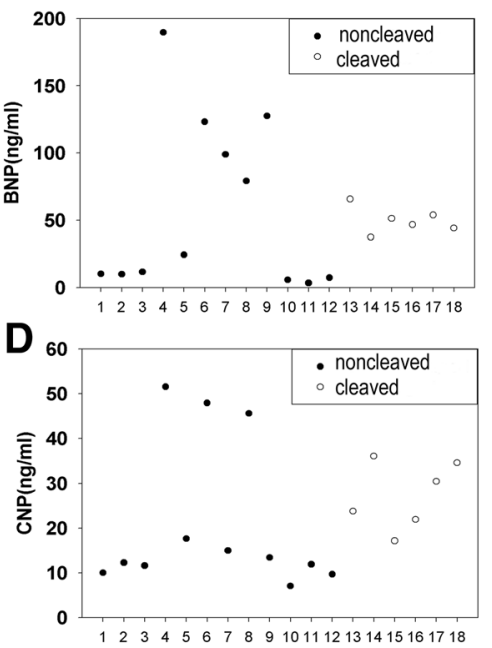

F

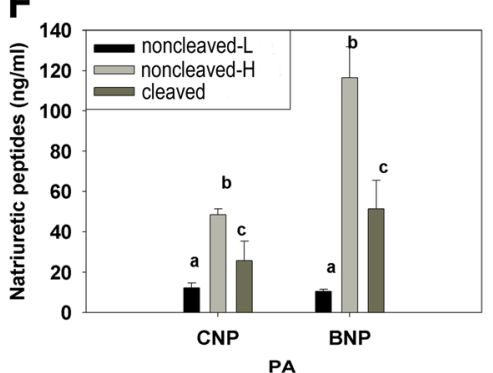

C

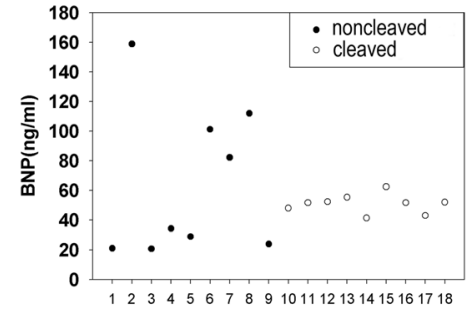

E

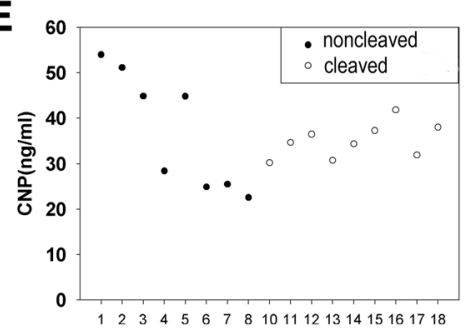

G

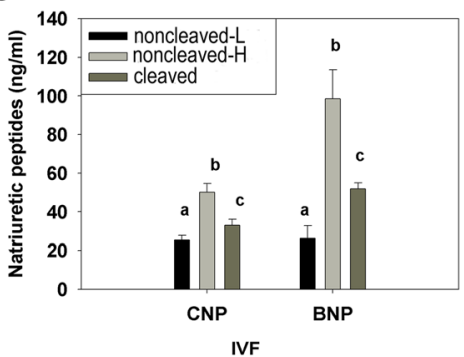

Fig. 2 Detected natriuretic peptides concentrations in single follicles, classified according to the cleavage potential after in vitro fertilization with COCs coming from such follicles. a The single COCs in vitro culture model. $\mathbf{b}$, $\mathbf{d}$ The concentrations of BNP, CNP in the follicular fluid of cleaved embryos $(n=6)$ and non cleaved embryos by culturing individually COCs from Single follicle in vitro and PA. $\mathbf{c}$, e The concentrations of BNP, CNP in the follicular fluid of cleaved embryos $(n=9)$ and non cleaved embryos by culturing individually COCs from Single follicle in vitro and IVF. $\mathbf{f}, \mathbf{g}$ The mean concentrations of BNP and CNP induced from $\mathbf{b}-\mathbf{e}$, in which the data from those were divided into three parts, the non-cleaved-low, the cleaved and the non-cleaved-high, as they were compared with the mean value. At least three follicles were examined at each time point for each experiment. The bars show the mean \pm SEM of data from three independent experiments. Different columns with various superscript letters differ significantly $(P<0.05)$

development rates were significantly higher in both BNP (12.6\%) and CNP (11.6\%) groups or cilostamide (8.8\%) than the controls, including $46 \mathrm{~h}(4.2 \%) \quad(P<0.01)$ (Table 5). The phenomenon was more obvious with PA experiment $(P<0.01)$ [BNP $(31.7 \%)$, CNP $(32.0 \%)$, cilostamide $(25.6 \%)$, control (12.6\%)]. The cleavage as well as blastocyst formation rates of BNP/CNP supplement groups were also significantly higher than the controls (Table 5). Similar to the cleavage rates, the blastocyst developmental rates of oocytes recovered from the 4.0 $6.0 \mathrm{~mm}$ follicles were increased significantly in the
PMC-BNP/CNP group than the controls $(P<0.05)$ [BNP (16.5\%),CNP (17.5\%), cilostamide (15.2\%), control (13.5\%)] (Table 6). But the blastocyst developmental rates of oocytes were decreased significantly $(P<0.05)$, which showed BNP (5.1\%), CNP (5.0\%), cilostamide (4.7\%), control (8.3\%) from 6.0 to $8.0 \mathrm{~mm}$ in the PMC$\mathrm{BNP} / \mathrm{CNP}$ group than the controls (Table 7). As a result, the different effects of NPs on developmental competence in immature porcine oocytes from follicles of different sizes in vitro, especially the developmental competence of oocytes from 3.0 to $4.0 \mathrm{~mm}$ (Fig. 4, a) in 


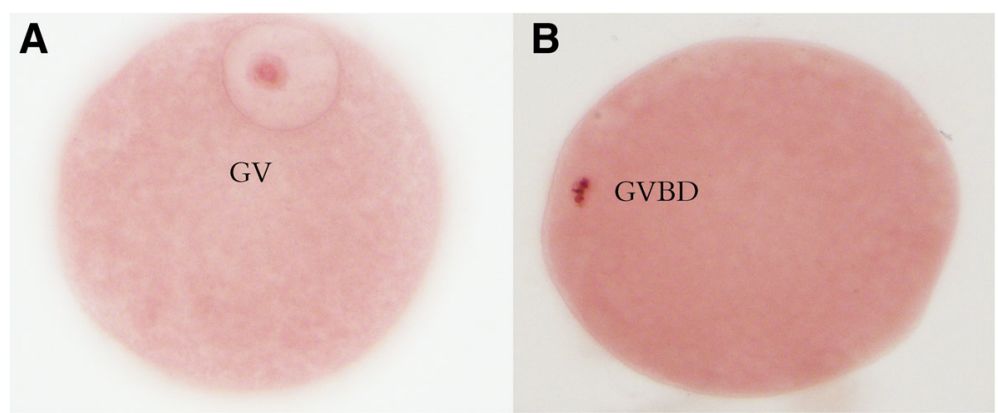

Fig. 3 The nuclear morphological feature of porcine oocytes at different developmental stage (a) Oocyte at the germinal vesicle stage (GV). $\mathbf{b}$ Oocyte that has undergone germinal vesicle breakdown (GVBD)

both PA and IVF groups were 2 to 3 folds higher than the controls $(P<0.01)$. These results indicated that BNP or CNP seem to be effective for improving the developmental competence of oocytes from such follicles.

\section{Discussion}

In the present study, the association of BNP and CNP on the developmental competence of porcine oocyte was studied in vivo or in vitro. Firstly, we analyzed the relative abundance of genes that were potentially involved in the oocyte competence using follicle size model. This model is well-established to identify the relationship between follicle size and oocyte developmental competence $[27,28]$. The relative $N P P B$ and NPPC mRNA expressions as well as the NP levels inside the follicular fluid in relation to follicle sizes indicated that the physiological levels of NPs at the set ranges contributed to the developmental competence of oocytes in follicles of 3.0$6.0 \mathrm{~mm}$ in size. There was an increase in $N P P B$ and NPPC mRNA levels in the follicles of 6.1-8.0 mm, but a decrease in protein content. According to existed studies, the granulosa cells were accumulated in large numbers during both early and late antral growth phases although the rate of accumulation declines when the follicle reaches the preovulatory phase $[29,30]$. In contrast

Table 3 The effects of both individual and combinations of BNP and CNP were evaluated by examining the GV stage on the resumption of $\mathrm{FSH}$-induced porcine COCs meiosis $($ mean \pm S. E. M.)

\begin{tabular}{lll}
\hline & oocytes(n) & GV(\%) \\
\hline Control(0 ng/mlBNP + 0 ng/mlCNP) & 124 & $24.3 \pm 1.3^{\mathrm{a}}$ \\
$100 \mathrm{ng} / \mathrm{mlBNP}+0 \mathrm{ng} / \mathrm{mlCNP}$ & 143 & $84.3 \pm 2.8^{\mathrm{b}}$ \\
$70 \mathrm{ng} / \mathrm{mlBNP}+30 \mathrm{ng} / \mathrm{mlCNP}$ & 138 & $84.9 \pm 3.2^{\mathrm{b}}$ \\
$50 \mathrm{ng} / \mathrm{mlBNP}+50 \mathrm{ng} / \mathrm{mlCNP}$ & 154 & $83.9 \pm 5.3^{\mathrm{b}}$ \\
$30 \mathrm{ng} / \mathrm{mlBNP}+70 \mathrm{ng} / \mathrm{mlCNP}$ & 127 & $84.3 \pm 3.5^{\mathrm{b}}$ \\
$0 \mathrm{ng} / \mathrm{mlBNP}+100 \mathrm{ng} / \mathrm{mlCNP}$ & 159 & $85.3 \pm 2.1^{\mathrm{b}}$ \\
\hline
\end{tabular}

At least three independent experiments were assessed at each point for each assay. ${ }^{a b}$ Means in the same column with different superscripts were significantly different $(p<0.01)$ to the follicular cells, antral fluid continues to accumulate until the time of ovulation. Indeed, during the preovulatory growth phase, follicular enlargement was due to fluid accumulation [31, 32]. Therefore, the lower concentration of NPs in the follicle size $6.0-8.0 \mathrm{~mm}$ attributed to a "dilution effect" due to the accumulation of follicular fluid rather than a reduced synthesisaccumulation of the peptides.

In order to trace the fate of individual follicles of different sizes and with various NP levels inside the follicular fluid, the COCs from 3.0 to $6.0 \mathrm{~mm}$ follicles were cultured individually. The results have shown that whenever the NP levels achieved a set range, the prognosis of oocytes that developed till the blastocyst stage with both PA and IVF assays demonstrated more positive follicles than those that have either higher or lower NP levels. Therefore, higher NP levels in individual follicles do not necessarily warrant a better oocyte developmental competence, rather, the NP levels sustained in the physiological range are more important for follicle development. Early reports have demonstrated that porcine BNP has high affinity to human $N P R B$ and rat $N P R B$ [4, 33], porcine BNP is as effective as porcine CNP to activate porcine $N P R B[16,34]$. The relationship between BNP and CNP in oocyte meiotic arrest was not clearly understood, nevertheless in this study, $100 \mathrm{ng} /$ $\mathrm{mL}$ of either individual or mixed BNP/CNP had similar

Table 4 The effects of NPs on the developmental competence of immature porcine oocytes from 3-8 mm follicles $($ mean \pm S. E. M.)

\begin{tabular}{llcc}
\hline & oocytes $(n)$ & cleaved oocytes (\%) & blastocysts (\%) \\
\hline Control & 305 & $36.0 \pm 1.9$ & $10.2 \pm 2.6$ \\
cilostamide & 318 & $36.9 \pm 2.6$ & $11.4 \pm 3.3$ \\
BNP & 369 & $36.6 \pm 3.8$ & $9.8 \pm 1.7$ \\
CNP & 256 & $37.2 \pm 1.6$ & $11.6 \pm 3.6$ \\
\hline
\end{tabular}

Cleavage rates on day 2 and Blastocyst developmental rates on day 7 after IVF of the COCs recovered from the $3.0-8.0 \mathrm{~mm}$ follicles in standard IVM for $46 \mathrm{~h}$ (as negative controls), or pre-cultured with PMCl-cilostamide $20 \mathrm{~h}$ plus IVM $46 \mathrm{~h}$ (as positive controls) and pre-cultured with PMCI-BNP/CNP $20 \mathrm{~h}$ plus IVM $46 \mathrm{~h}$ (as experimental groups) 
Table 5 The effects of NPs on the developmental competence of immature porcine oocytes from 3.0-4.0 mm follicles (mean \pm S. E. M.)

\begin{tabular}{|c|c|c|c|c|c|c|}
\hline \multirow{2}{*}{ 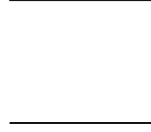 } & \multicolumn{3}{|l|}{ IVF } & \multicolumn{3}{|l|}{ PA } \\
\hline & Oocytes (n) & cleaved oocytes (\%) & blastocysts (\%) & $\begin{array}{l}\text { Oocytes } \\
\text { (n) }\end{array}$ & cleaved oocytes (\%) & blastocysts (\%) \\
\hline Control & 326 & $11.3 \pm 1.9^{a}$ & $4.2 \pm 1.0^{a}$ & 264 & $31.6 \pm 2.5^{a}$ & $12.6 \pm 1.1^{\mathrm{a}}$ \\
\hline cilostamide & 328 & $38.5 \pm 1.7^{b}$ & $8.8 \pm 1.7^{b}$ & 256 & $70.4 \pm 3.7^{b}$ & $25.6 \pm 1.4^{b}$ \\
\hline BNP & 314 & $40.5 \pm 2.7^{b}$ & $12.6 \pm 2.5^{c}$ & 311 & $81.1 \pm 2.3^{c}$ & $31.7 \pm 2.3^{c}$ \\
\hline CNP & 289 & $41.4 \pm 2.8^{b}$ & $11.6 \pm 1.6^{c}$ & 288 & $78.4 \pm 3.2^{c}$ & $32.0 \pm 2.4^{c}$ \\
\hline
\end{tabular}

Cleavage rates on day 2 and Blastocyst developmental rates on day 7 after IVF and PA of the COCs recovered from the $3.0-8.0 \mathrm{~mm}$ follicles in standard IVM for $46 \mathrm{~h}$ (as negative controls), or pre-cultured with PMCl-cilostamide $20 \mathrm{~h}$ plus IVM $46 \mathrm{~h}$ (as positive controls) and pre-cultured with PMCI-BNP/CNP $20 \mathrm{~h}$ plus IVM $46 \mathrm{~h}$ (as experimental groups). ${ }^{\text {abc }}$ Means in the same column with different superscripts were significantly different $(p<0.01)$

inhibitory effect on oocyte nuclear maturation of in vitro cultured COCs. The set values of NPs were proved to be $80-100 \mathrm{ng} / \mathrm{mL}$ of total NPs with $45-65 \mathrm{ng} / \mathrm{mL}$ of BNP and $30-45 \mathrm{ng} / \mathrm{mL}$ of CNP each. In this study, the follicles with set values of NPs were proved to have a higher oocyte developmental competence than the follicles whose NP values were deviated from these set values. Therefore, higher NP levels in individual follicles do not necessarily warrant a better oocyte developmental potential, rather the NP levels sustained in the physiological range are more important for follicle development.

Oocytes from small antral follicles have a poor capacity to support embryogenesis till the blastocyst stage, but oocytes from large antral follicles have higher developmental competence [2, 35-38]. Sustaining at the set ranges of NP concentrations in the whole process of follicular growth stage is important for the oocytes to acquire developmental competence, and might require a long period of time to accumulate a greater amount of maternal mRNA and protein in cytoplasm [38]. Oocytes gradually and sequentially acquire increase in the developmental competence with advanced folliculogenesis [38]. Follicles in 6.1$8.0 \mathrm{~mm}$ might undergo atresia that explains both the lower protein synthesis and lower developmental competence $[39,40]$. The preparation before ovulation may lower NP levels [17] and demonstrated that the NPs have function in the developmental competence. The oocyte developmental competence was influenced by other

Table 6 The effects of NPs on the developmental competence of immature porcine oocytes from 4.1-6.0 $\mathrm{mm}$ follicles $($ mean \pm S. E. M.)

\begin{tabular}{llcc}
\hline & oocytes $(\mathrm{n})$ & cleaved oocytes (\%) & blastocysts (\%) \\
\hline control & 214 & $40.5 \pm 1.42^{\mathrm{a}}$ & $13.5 \pm 2.9^{\mathrm{a}}$ \\
cilostamide & 267 & $47.2 \pm 2.04^{\mathrm{ab}}$ & $15.2 \pm 1.5^{\mathrm{ab}}$ \\
BNP & 245 & $52.1 \pm 2.01^{\mathrm{b}}$ & $16.5 \pm 2.6^{\mathrm{b}}$ \\
CNP & 223 & $51.9 \pm 1.28^{\mathrm{b}}$ & $17.6 \pm 2.3^{\mathrm{b}}$ \\
\hline
\end{tabular}

Cleavage rates on day 2 and Blastocyst developmental rates on day 7 after IVF of the COCs recovered from the $4.1-6.0 \mathrm{~mm}$ follicles in standard IVM for $46 \mathrm{~h}$ (as negative controls), or pre-cultured with $\mathrm{PMCl}$-cilostamide $20 \mathrm{~h}$ plus IVM $46 \mathrm{~h}$ (as positive controls) and pre-cultured with PMCI-BNP/CNP $20 \mathrm{~h}$ plus IVM $46 \mathrm{~h}$ (as experimental groups). ${ }^{\mathrm{ab}}$ Means in the same column with different superscripts were significantly different $(p<0.05)$ factors in $3.0-4.0$ or $6.1-8.0 \mathrm{~mm}$ follicles, while the concentrations of NPs in follicles that may not reflect oocyte developmental competence completely. So the cleavage and blastocyst rates of oocytes in $3.0-4.0 \mathrm{~mm}$ follicles did not match the cleavage and blastocyst rates of oocytes in $4.1-6.0 \mathrm{~mm}$ follicles. But the blastocyst developmental rates of oocytes recovered from 3.0 to $4.0 \mathrm{~mm}$ follicles showed a significant increase in the pre-culture with PMCI-BNP/CNP. The decrease in the NPs concentrations in follicles $6.1-8.0 \mathrm{~mm}$ was minimal $(1-8 \mathrm{ng} / \mathrm{ml})$, but showed a major drop in the blastocyst rate. The NPs in PMC media could not improve the blastocyst developmental rates of the oocytes in $6.1-8.0 \mathrm{~mm}$ follicles compared to the NP concentrations in the original follicle.

The deficient IVM outcome is mostly a result of the asynchrony between nuclear and cytoplasmic maturation $[4,6]$. It has been hypothesized that an in vitro prematuration period of oocytes retrieved from the antral follicles might lead to an improved oocyte cytoplasmic maturation [4, 6, 8, 9, 41]. PMC can only be achieved by blocking the inevitably spontaneous nuclear maturation that starts immediately after the oocyte that has been disconnected from the somatic compartment of the follicle, and extending the period of GV-stage arrest in PMC might alleviate this asynchrony by allowing time for completion of cytoplasmic maturity $[4,6,42,43]$. As reported, the path to cytoplasmic competence included the buildup and

Table 7 The effects of NPs on the developmental competence of immature porcine oocytes from 6.1-8.0 mm follicles $($ mean \pm S. E. M.)

\begin{tabular}{llcc}
\hline & oocytes $(\mathrm{n})$ & cleaved oocytes (\%) & blastocysts (\%) \\
\hline Control & 294 & $30.9 \pm 1.1^{\mathrm{a}}$ & $8.3 \pm 1.7^{\mathrm{a}}$ \\
cilostamide & 263 & $23.2 \pm 2.3^{\mathrm{b}}$ & $4.7 \pm 2.4^{\mathrm{b}}$ \\
BNP & 301 & $25.1 \pm 1.6^{\mathrm{b}}$ & $5.1 \pm 3.3^{\mathrm{b}}$ \\
CNP & 268 & $24.6 \pm 1.0^{\mathrm{b}}$ & $5.0 \pm 1.8^{\mathrm{b}}$ \\
\hline
\end{tabular}

Cleavage rates on day 2 and Blastocyst developmental rates on day 7 after IVF of the COCs recovered from the $6.1-8.0 \mathrm{~mm}$ follicles in standard IVM for $46 \mathrm{~h}$ (as negative controls), or pre-cultured with PMCl-cilostamide $20 \mathrm{~h}$ plus IVM $46 \mathrm{~h}$ (as positive controls) and pre-cultured with PMCI-BNP/CNP $20 \mathrm{~h}$ plus IVM $46 \mathrm{~h}$ (as experimental groups). ${ }^{\mathrm{ab}}$ Means in the same column with different superscripts were significantly different $(p<0.05)$ 


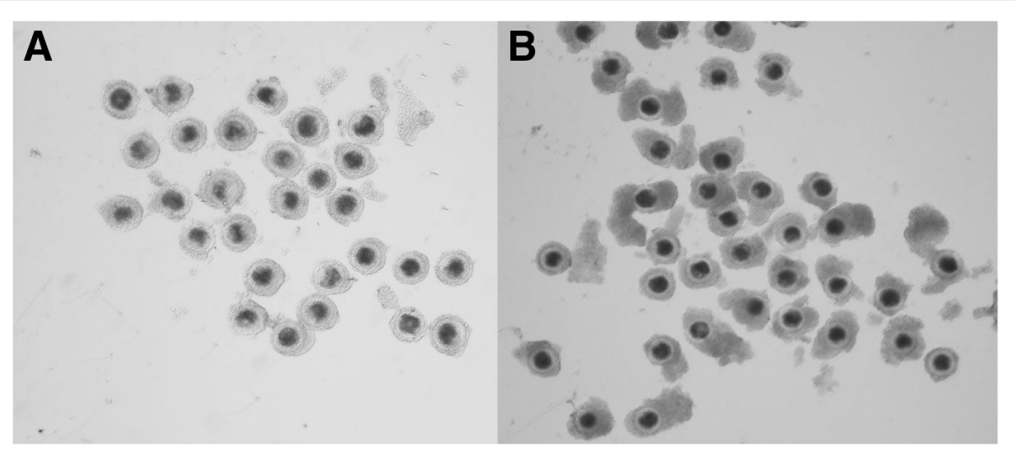

Fig. 4 COCs recovered from (a) the $3.0-4.0 \mathrm{~mm}$ antral follicles, (b) the $4.1-8.0 \mathrm{~mm}$ antral follicles

storage of transcripts [44-46], synthesis and accumulation of proteins, posttranslational modifications, and ultrastructural changes. The meiotic arrest can be induced pharmacologically by manipulating the intraoocyte cAMP levels $[4,6]$. Consequently, the PDE inhibitors were widely used in humans [6], mouse [6], bovine $[4,8]$, and porcine during the PMC process. In the present study, the cleavage and blastocyst developmental rates of oocytes recovered from the 3.0 $6.0 \mathrm{~mm}$ follicles was increased significantly in preculture with PMCI-BNP/CNP and PMCI-cilostamide. Therefore, it is reasonable to believe that NPs, which are naturally present inside the follicular fluid could be even more beneficial than pharmacologically treated for the development of PMC systems that aimed at enhancing the outcomes of IVM protocols.

Previous study has proved that applying PDE isoenzyme inhibitor (rolipram; $100 \mathrm{mM}$ )) significantly increased the blastocyst development (an increase from 34 to $51 \%$ compared to the control to the blastocysts) when bovine oocytes were fertilized at $28 \mathrm{~h}$ [4]. However, in this research, the PMC strategy with NPs showed no obvious contribution to the blastocyst development if porcine COCs were from the 3.0 $8.0 \mathrm{~mm}$ antral follicles. The mixed oocyte population collected from 3.0 to $8.0 \mathrm{~mm}$ follicles demonstrated that the PMC treatment has the potential to positively affect only a subset of the total collected oocytes, while others would not benefit from this culture strategy. Also, some oocytes were derived from the early atretic follicles $[47,48]$, and instead were negatively affected by prolongation of culture. The cleavage and blastocyst developmental rates of oocytes recovered from the $3.0-6.0 \mathrm{~mm}$ follicles was increased significantly in the pre-culture with $\mathrm{PMCI}-\mathrm{BNP} / \mathrm{CNP}$, while that in the $6.1-6.8 \mathrm{~mm}$ was decreased. Notably, the COCs recovered from the $3.0-4.0 \mathrm{~mm}$ follicles were cultured in the same in vitro system and presented significant effects on oocyte developmental competence, and the ratio of blastocysts was elevated by 2 to 3 folds compared to the controls. Therefore, we stated here that the effect of NPs on the developmental competence of immature porcine oocytes from follicles of different sizes was different in vitro.

\section{Conclusions}

The effect of NPs on the developmental competence of immature porcine oocytes from follicles with different size was different in vitro. In the growing follicles, especially in $3.0-6.0 \mathrm{~mm}$ follicles, the appropriate maintenance of NP concentration is important for its developmental competence. Administration of NPs to the PMC media was specifically efficient for the antral follicles of $3.0-4.0 \mathrm{~mm}$ size to achieve better oocyte developmental competence. Our findings contribute to improve the oocyte developmental competence in porcine in vitro.

\section{Additional file}

Additional file 1: Table S1. Primers used for quantitative real-time PCR. (DOC $30 \mathrm{~kb}$ )

\section{Abbreviations \\ ANOVA: Analysis of variance; BNP: Brain natriuretic peptide; CAMP: Cyclic adenosine monophosphate; CGMP: Cyclic guanosine monophosphate; CNP: C-Type natriuretic peptide; COC: Cumulus oocyte complexes; FCS: Fetal calf serum; GAPDH: Glyceraldehyde-3-phosphate dehydrogenase; GJC: Gap junction mediated communication; GV: Germinal vesicle; GVBD: Germinal vesicle breakdown; hCG: Human chorionic gonadotropin; IVF: In vitro fertilization; IVM: In vitro matured; NPs: Natriuretic peptides; \\ PA: Parthenogenetic activation; PDE3 A: Phosphodiesterase 3A; PMC: Pre-maturation culture; PMSG: Pregnant mare's serum gonadotropin; PZM: Porcine zygote medium; qRT-PCR: Quantitative real-time polymerase chain reaction}

\section{Acknowledgments}

Not applicable.

\section{Funding}

This work was supported by the National Basic Research Program of China (973 Program: 2013CB945501: 2014CB138503: 2014CB943202). 


\section{Availability of data and materials}

The datasets supporting the conclusions of this article are included within the article.

\section{Authors' contributions}

$Y Z$ designed and conducted the experiments and wrote the initial draft of the manuscript. HW, WL, YY, XW, ZZ, QG, CW, and GX helped with image analysis and oocyte counts. CW and GX helped with experimental design data analysis and interpretation and manuscript editing. In addition, GX obtained funding to support the project. All authors read and approved the final manuscript.

\section{Competing interests}

There is no conflict of interest that could be perceived as prejudicing the impartiality of the research reported.

\section{Consent for publication}

Not applicable.

\section{Ethics approval and consent to participate}

All the experiments were performed in accordance with the guidelines of the Animal Ethics Committee of China Agricultural University. The study protocol was approved by the Animal Care and Use Committee of China Agricultural University.

\section{Publisher's Note}

Springer Nature remains neutral with regard to jurisdictional claims in published maps and institutional affiliations.

Received: 23 December 2016 Accepted: 15 May 2017 Published online: 30 May 2017

\section{References}

1. Zhang J, et al. Effect of C-Type natriuretic peptide on maturation and developmental competence of goat oocytes matured in vitro. PLoS One. 2015;10(7):e0132318

2. Eppig JJ, et al. Relationship between the developmental programs controlling nuclear and cytoplasmic maturation of mouse oocytes. Dev Biol. 1994;164(1):1-9.

3. Albuz FK, et al. Simulated physiological oocyte maturation (SPOM): a novel in vitro maturation system that substantially improves embryo yield and pregnancy outcomes. Hum Reprod. 2010;25(12):2999-3011.

4. Thomas RE, et al. Effect of specific phosphodiesterase isoenzyme inhibitors during in vitro maturation of bovine oocytes on meiotic and developmental capacity. Biol Reprod. 2004;71(4):1142-9.

5. Sirard MA, et al. Contribution of the oocyte to embryo quality. Theriogenology. 2006:65(1):126-36.

6. Nogueira D, et al. Effect of phosphodiesterase type 3 inhibitor on developmental competence of immature mouse oocytes in vitro. Biol Reprod. 2003;69(6):2045-52.

7. Luciano AM, et al. Gap junction-mediated communications regulate chromatin remodeling during bovine oocyte growth and differentiation through CAMP-dependent mechanism(s). Biol Reprod. 2011;85(6):1252-9.

8. Franciosi F, et al. Natriuretic peptide precursor $C$ delays meiotic resumption and sustains gap junction-mediated communication in bovine cumulus-enclosed oocytes. Biol Reprod. 2014;91(3):61.

9. Anderiesz C, et al. Regulation of human and mouse oocyte maturation in vitro with 6-dimethylaminopurine. Hum Reprod. 2000;15(2):379-88.

10. Potter $L R$, et al. Natriuretic peptides: their structures, receptors, physiologic functions and therapeutic applications. Handb Exp Pharmacol. 2009;191:341-66.

11. de Bold AJ, et al. A rapid and potent natriuretic response to intravenous injection of atrial myocardial extract in rats. Life Sci. 1981;28(1):89-94.

12. Sudoh $T$, et al. A new natriuretic peptide in porcine brain. Nature. 1988;332(6159):78-81.

13. Sudoh T, et al. C-type natriuretic peptide (CNP): a new member of natriuretic peptide family identified in porcine brain. Biochem Biophys Res Commun. 1990;168(2):863-70.

14. Zhang M, et al. Granulosa cell ligand NPPC and its receptor NPR2 maintain meiotic arrest in mouse oocytes. Science. 2010;330(6002):366-9.
15. Zhang $M$, et al. Estradiol promotes and maintains cumulus cell expression of natriuretic peptide receptor 2 (NPR2) and meiotic arrest in mouse oocytes in vitro. Endocrinology. 2011;152(11):4377-85.

16. Zhang $W$, et al. Brain natriuretic peptide and C-type natriuretic peptide maintain porcine oocyte meiotic arrest. J Cell Physiol. 2015;230(1):71-81.

17. Kawamura K, et al. Pre-ovulatory LH/hCG surge decreases C-type natriuretic peptide secretion by ovarian granulosa cells to promote meiotic resumption of pre-ovulatory oocytes. Hum Reprod. 2011;26(11):3094-101.

18. Hiradate $Y$, et al. C-type natriuretic peptide inhibits porcine oocyte meiotic resumption. Zygote. 2014;22(3):372-7.

19. Zhang $Y$, et al. Porcine natriuretic peptide type $B$ (pNPPB) maintains mouse oocyte meiotic arrest via natriuretic peptide receptor 2 (NPR2) in cumulus cells. Mol Reprod Dev. 2014;81(5):462-9.

20. Santiquet $\mathrm{N}$, et al. New elements in the C-type natriuretic peptide signaling pathway inhibiting swine in vitro oocyte meiotic resumption. Biol Reprod. 2014;91(1):16

21. Wei Q, et al. Effect of C-type natriuretic peptide on maturation and developmental competence of immature mouse oocytes in vitro. Reprod Fertil Dev. 2015;10(7).

22. Appeltant $\mathrm{R}$, et al. Increasing the CAMP concentration during in vitro maturation of pig oocytes improves cumulus maturation and subsequent fertilization in vitro. Theriogenology. 2015;83(3):344-52.

23. Vanderhyden GMKB. Bidirectional communication between oocytes and follicle cells: ensuring oocyte developmental competence. Can J Physiol Pharmacol. 2010;88(4):399-413.

24. Dieci $C$, et al. The effect of cilostamide on gap junction communication dynamics, chromatin remodeling, and competence acquisition in pig oocytes following parthenogenetic activation and nuclear transfer. Biol Reprod. 2013;89(3):68.

25. Yoshioka $\mathrm{K}$, et al. Birth of piglets derived from porcine zygotes cultured in a chemically defined medium. Biol Reprod. 2002;66(1):112-9.

26. Kwak SS, et al. The effects of resveratrol on porcine oocyte in vitro maturation and subsequent embryonic development after parthenogenetic activation and in vitro fertilization. Theriogenology. 2012;78(1):86-101.

27. Qian $Y$, et al. Predictive value of the area of expanded cumulus mass on development of porcine oocytes matured and fertilized in vitro. J Reprod Dev. 2003;49(2):167-74.

28. Lequarre AS, et al. Influence of antral follicle size on oocyte characteristics and embryo development in the bovine. Theriogenology. 2005;63(3):841-59.

29. Bomsel-Helmreich $\mathrm{O}$, et al. Healthy and atretic human follicles in the preovulatory phase: differences in evolution of follicular morphology and steroid content of follicular fluid. J Clin Endocrinol Metab. 1979;48(4):686-94

30. Griffin J, et al. Comparative analysis of follicle morphology and oocyte diameter in four mammalian species (mouse, hamster, pig, and human). J Exp Clin Assist Reprod. 2006:3:2.

31. MCNatty KP. Hormonal correlates of follicular development in the human ovary. Aust J Biol Sci. 1981;34(3):249-68.

32. Baerwald AR, Adams GP, Pierson RA. Characterization of ovarian follicular wave dynamics in women. Biol Reprod. 2003;69(3):1023-31.

33. Mermillod $\mathrm{P}$, et al. High developmental competence of cattle oocytes maintained at the germinal vesicle stage for $24 \mathrm{~h}$ in culture by specific inhibition of MPF kinase activity. Mol Reprod Dev. 2000;55(1):89-95.

34. Zhang $W$, et al. Epidermal growth factor-network signaling mediates luteinizing hormone regulation of BNP and CNP and their receptor NPR2 during porcine oocyte meiotic resumption. Mol Reprod Dev. 2014;81(11):1030-41.

35. Bagg MA, et al. Relationship between follicle size and oocyte developmental competence in prepubertal and adult pigs. Reprod Fertil Dev. 2007;19(7):797-803.

36. Hu Y, et al. Effects of low $\mathrm{O} 2$ and ageing on spindles and chromosomes in mouse oocytes from pre-antral follicle culture. Hum Reprod. 2001;16(4):737-48.

37. Sugimura $\mathrm{S}$, et al. Promotion of EGF receptor signaling improves the quality of low developmental competence oocytes. Dev Biol. 2015;403(2):139-49.

38. Eppig JJ, Schroeder AC, O'Brien MJ. Developmental capacity of mouse oocytes matured in vitro: effects of gonadotrophic stimulation, follicular origin and oocyte size. J Reprod Fertil. 1992;95(1):119-27.

39. Lonergan $\mathrm{P}$, et al. Effect of follicle size on bovine oocyte quality and developmental competence following maturation, fertilization, and culture in vitro. Mol Reprod Dev. 1994;37(1):48-53.

40. Gilchrist RB, Lane M, Thompson JG. Oocyte-secreted factors: regulators of cumulus cell function and oocyte quality. Hum Reprod Update. 2008;14(2):159-77 
41. Hashimoto $S$, et al. Bovine immature oocytes acquire developmental competence during meiotic arrest in vitro. Biol Reprod. 2002;66(6):1696-701.

42. Caixeta ES, et al. Effect of follicle size on mRNA expression in cumulus cells and oocytes of Bos indicus: an approach to identify marker genes for developmental competence. Reprod Fertil Dev. 2009;21(5):655-64.

43. Wu GM, et al. High developmental competence of pig oocytes after meiotic inhibition with a specific M-phase promoting factor kinase inhibitor, butyrolactone I. Biol Reprod. 2002;67(1):170-7.

44. Bianchi L, et al. Protein pathways working in human follicular fluid: the future for tailored IVF? Expert Rev Mol Med. 2016;18:e9.

45. Ceelen $\mathrm{M}$, et al. Cardiometabolic differences in children born after in vitro fertilization: follow-up study. J Clin Endocrinol Metab. 2008;93(5):1682-8.

46. Levesque JT, Sirard MA. Effects of different kinases and phosphatases on nuclear and cytoplasmic maturation of bovine oocytes. Mol Reprod Dev. 1995;42(1):114-21.

47. Lodde $\mathrm{V}$, et al. Oocyte morphology and transcriptional silencing in relation to chromatin remodeling during the final phases of bovine oocyte growth. Mol Reprod Dev. 2008;75(5):915-24.

48. Lodde V, et al. Large-scale chromatin remodeling in germinal vesicle bovine oocytes: interplay with gap junction functionality and developmental competence. Mol Reprod Dev. 2007;74(6):740-9.

\section{Submit your next manuscript to BioMed Central} and we will help you at every step:

- We accept pre-submission inquiries

- Our selector tool helps you to find the most relevant journal

- We provide round the clock customer support

- Convenient online submission

- Thorough peer review

- Inclusion in PubMed and all major indexing services

- Maximum visibility for your research

Submit your manuscript at www.biomedcentral.com/submit 